\title{
Level of physical activity and associated factors during pregnancy among women who gave birth in Public Zonal Hospitals of Tigray
}

\author{
Dawit Gebregziabher ${ }^{1 *}$, Haftu Berhe ${ }^{2}$, Mekuria Kassa ${ }^{2}$ and Eskedar Berhanie ${ }^{1}$
}

\begin{abstract}
Objectives: Physical activity in the general population is considered too low, and this is true for pregnant women. Moderate physical activity during pregnancy have many benefits for the mother and the developing baby. This study was aimed to assess the level of physical activity during pregnancy and associated factors in public zonal hospitals of Tigray, Ethiopia. A hospital based cross-sectional study was used and 458 study participants was selected using multistage sampling technique. The data were collected using standardized pregnancy physical activity questionnaire.

Result: Out of 442 women who participated in this study, only $21.9 \%$ were physically inactive. Parity [AOR $=7.68$; $95 \% \mathrm{Cl}(3.193,18.459)]$, maternal occupation $[\mathrm{AOR}=.015 ; 95 \% \mathrm{Cl}(.003, .083)]$, history of miscarriage $[\mathrm{AOR}=8.045$; $95 \% \mathrm{Cl}(3.325,19.465)]$, maternal age $\mathrm{AOR}=4.67 ; 95 \% \mathrm{Cl}(1.431,15.254)]$, were the variables that showed statistical association with level of physical activity during pregnancy. Level of physical activity during pregnancy was generally high. Thus, it would be optimal if health professionals can take a more active role in promoting physical activity during pregnancy.
\end{abstract}

Keywords: Physical activity, Exercise

\section{Introduction}

Physical activity is an important component of a healthy pregnancy, for both the mother and her child. Physical activity has been accepted internationally as an important factor for the protection and improvement of health in pregnant women as well as in the general population. Being physically active is recognized as an essential part of a healthy pregnancy and is associated with improved cardiovascular function and physical fittness and reduced risk of adverse maternal outcomes including gestational diabetes, preeclampsia and preterm birth $[1,2]$.

According to the World Health Organization recommendations, adults aged 18 to 64 years should have at least $150 \mathrm{~min}$ of moderate-intensity, or $75 \mathrm{~min}$ of vigorous-intensity aerobic physical activity throughout the week, or an equivalent combination of both [3].

\footnotetext{
*Correspondence: dawit23natieku@gmail.com

${ }^{1}$ Lecturer at Nursing School, College of Health Science, Aksum University, Aksum, Ethiopia

Full list of author information is available at the end of the article
}

The Centers for disease control and prevention (CDC), American college of sports medicine (ACSM) adopted this recommendation for pregnant women and advised engagement in $30 \mathrm{~min}$ of moderate exercise per day on most days of the week, equivalent to 7.5 MET-h/week [4].

Globally, around 23\% of adults aged 18 and over were not active enough in 2010 (men 20\% and women 27\%). Only $10.2 \%$ of women fulfilled the recommendations in Brazil, $17.4 \%$ in United States, $20.3 \%$ in Spain, $47 \%$ in France, and 48\% in United Kingdom [5-10].

Proper and adequate physical activity during pregnancy has a major impact on mother's health and fetal growth. The earliest recommendations for PA during pregnancy largely reflected the cultural and social norms of the times, rather than scientific evaluation [11-15]. Even though physical activity during pregnancy is beneficial in the absence of medical or obstetric complications, most of the pregnant women's may not perceive it safe appropriate and feasible. This is mainly due to lack of information on physical activity during pregnancy, safety issue and cultural norms [16-18]. 
The finding of this study would, be potentially useful in generating previously unavailable data on the level of physical activity during pregnancy, therefore policy makers and NGOs may use this for future planning and public health interventions of appropriate strategies to prevent pregnancy comorbidities and promote maternal and fetal health.

\section{Main text}

\section{Materials and methods}

This study was conducted in three randomly selected zonal public hospitals of Tigray Regional state of Northern Ethiopia from Oct. 2016 up to May 2017. Tigray is one of the nine ethnic regions in Ethiopia. Tigray is divided into 47 districts (woredas) which are grouped into six administrative zones like Eastern zone, Central Zone, North Western Zone, Southern Zone, Western Zone, Mekelle (special zone). The study design was hospital based cross-sectional study design [19].

The study population includes sampled women who gave birth in selected Zonal Hospitals of Tigray. A total of 458 samples was employed among the three selected zonal hospitals using systematic random sampling.

Data was collected using standardized pregnancy physical activity questionnaire (See Additional file 1) [20]. The intensity of each activity was estimated using 2011 compendium-based metabolic equivalent (MET) values. The intensity of activities was multiplied by the duration of time spent on each activity to get average weekly energy expenditure. Metabolic equivalent task was (1 $\mathrm{MET}=1 \mathrm{kcal} / \mathrm{kg} \times$ hour) values was used to classify each activity by intensity [21]. Data was entered using Epi info version 7, cleaned and analyzed using Statistical package for social sciences version 22.0 software. Descriptive statistics was used to characterize the sample. Logistic regression was used to assess statistical association and significance of statistical association was assured or tested using $95 \%$ confidence interval and $\mathrm{P}$ value $(<.05)$. Ethical clearance was secured from the Mekelle University, college of health science institutional review board. Oral and written consent was obtained from each participant. Information was recorded anonymously and confidentiality and beneficence were assured throughout the study period.

\section{Result}

\section{Maternal socio demographic characteristics}

A total of 458 women aged 18-38 participated in the study giving over all response rates of $96.5 \%$. The reasons for non-response were: incomplete physical activity data due to missing activity recordings $(\mathrm{n}=11)$, refusal to participate $(\mathrm{n}=5)$. The median ( \pm IQ range) of age of mothers were $26 \pm 08$ years range from $18-38$ years. Two hundred and seventy-two (60.9\%) of the respondents were in the age range of 25-40 years (Table 1).

\section{Maternal obstetrics characteristics}

Four hundred thirty (97.3\%) of women had received ANC service at least once during the index of pregnancy. Only $90(20.4 \%)$ of the women reported previous history of miscarriage. The median ( \pm IQ range) of parity was $1 \pm$ 2 ranges from 1 to 8 live births and more than half 247 (55.9) were multiparous and $341(77.1 \%)$ of the pregnancy were planned (Table 2).

Table 1 Distribution of socio-demographic characteristics of women by the level of physical activity during pregnancy in selected zonal hospitals of Tigray, Ethiopia $(n=442)$, 2017

\begin{tabular}{|c|c|c|c|c|}
\hline \multirow[t]{3}{*}{ Variables } & \multirow[t]{3}{*}{ Category } & \multirow[t]{3}{*}{ Total (\%) } & \multicolumn{2}{|l|}{ Level of PA } \\
\hline & & & Active & Inactive \\
\hline & & & $\mathrm{n}=345(\%)$ & $n=97(\%)$ \\
\hline \multicolumn{5}{|l|}{ Age (years) } \\
\hline & $<19$ & $36(8.1)$ & $22(6.4)$ & $14(14.4)$ \\
\hline & $20-24$ & $134(31.0)$ & $107(31.0)$ & $27(27.8)$ \\
\hline & $25-29$ & $154(34.8)$ & $124(35.9)$ & $30(30.9)$ \\
\hline & $30-34$ & $81(18.3)$ & $69(20)$ & $12(12.4)$ \\
\hline & $35-40$ & $137(8.4)$ & $23(6.7)$ & $14(14.4)$ \\
\hline \multicolumn{5}{|c|}{ Marital status } \\
\hline & Married & $384(86.9)$ & $310(89.9)$ & $74(76.3)$ \\
\hline & Never married & $30(6.8)$ & $15(4.3)$ & $15(15.5)$ \\
\hline & Divorced/widowed & $28(6.3)$ & $20(5.8)$ & $8(8.2)$ \\
\hline \multicolumn{5}{|c|}{ Education level } \\
\hline & Illiterate & $68(15.4)$ & $26(7.5)$ & $42(43.3)$ \\
\hline & Elementary school & $140(31.7)$ & $130(37.7)$ & $10(10.3)$ \\
\hline & High school & $142(32.1)$ & $117(33.9)$ & $25(25.8)$ \\
\hline & College/university & $92(20.8)$ & $72(20.9)$ & $20(20.6)$ \\
\hline \multicolumn{5}{|l|}{ Occupation } \\
\hline & House wife & $150(33.9)$ & $95(27.5)$ & $55(56.7)$ \\
\hline & Govt. employee & $90(20.4)$ & $72(20.9)$ & $18(18.6)$ \\
\hline & Private employee & $63(14.3)$ & $55(15.9)$ & $08(8.2)$ \\
\hline & Farmer & $95(21.5)$ & $91(26.4)$ & $04(4.1)$ \\
\hline & Trader & $22(5.0)$ & $18(5.2)$ & $04(4.1)$ \\
\hline & Student & $22(5.0)$ & $14(4.1)$ & $8(8.2)$ \\
\hline \multicolumn{5}{|c|}{ Income ${ }^{a}(n=394)$} \\
\hline & $<1000$ birr & $104(23.5)$ & $89(27.1)$ & $15(18.3)$ \\
\hline & $1001-1500$ & $44(10)$ & $35(10.7)$ & $9(11)$ \\
\hline & $1501-2000$ & $82(18.6)$ & $70(21.3)$ & $12(14.6)$ \\
\hline & $2001-3000$ & $108(24.4)$ & $81(24.7)$ & 27 (32.9) \\
\hline & 3001-above & $72(16.3)$ & $53(16.2)$ & $19(23.2)$ \\
\hline
\end{tabular}

${ }^{a}$ Cell counts may not add up to total number of participants due to missing values 
Table 2 Distribution of obstetrics characteristics of women by their level of physical activity during pregnancy in selected zonal hospitals of Tigray, Ethiopia, 2017 $(n=442)$

\begin{tabular}{|c|c|c|c|c|}
\hline \multirow[t]{2}{*}{ Variables } & \multirow[t]{2}{*}{ Category } & \multirow[t]{2}{*}{ Frequency (\%) } & \multicolumn{2}{|l|}{ Level of PA } \\
\hline & & & $\begin{array}{l}\text { Active } \\
n=345(\%)\end{array}$ & $\begin{array}{l}\text { Inactive } \\
n=97(\%)\end{array}$ \\
\hline \multicolumn{5}{|c|}{ ANC follow up } \\
\hline & No & $12(2.7)$ & $10(2.9)$ & $2(2.1)$ \\
\hline & Yes & $430(97.3)$ & $335(97.1)$ & 95 (97.9) \\
\hline \multicolumn{5}{|c|}{ ANC type $^{a}(n=430)$} \\
\hline & Public ANC & $286(66.5)$ & $212(61.4)$ & $74(76.3)$ \\
\hline & Private ANC & $144(33.5)$ & $123(35.7)$ & $21(21.6$ \\
\hline \multicolumn{5}{|c|}{ Pregnancy intention } \\
\hline & Planned & $341(77.1)$ & $290(84.1)$ & $51(52.6)$ \\
\hline & Unplanned & $101(22.9)$ & $55(15.9)$ & $46(47.4)$ \\
\hline \multicolumn{5}{|l|}{ Parity } \\
\hline & 1 primipara & $195(44.1)$ & $125(36.2))$ & 70 (72.2) \\
\hline & $\geq 2$ multipara & $247(55.9)$ & $220(63.8)$ & $27(27.8)$ \\
\hline \multicolumn{5}{|c|}{ History of miscarriage } \\
\hline & No & $352(79.6)$ & $288(83.5)$ & $64(66.0)$ \\
\hline & Yes & $90(20.4)$ & $57(16.5)$ & $33(34)$ \\
\hline
\end{tabular}

a Cell counts may not add up to total number of participants due to missing values

\section{Physical activity characteristics of women during pregnancy}

The median total weekly energy expenditure (MET-h/ week) of physical activity during the entire trimester of pregnancy was 141.23 MET-h/weeks [(Mean \pm SD) 140 $\pm 62.46]$. More than three fourth 345 (78.1\%) of women were doing $30 \mathrm{~min}$ or more of moderate-intensity physical activity on most days of the week and the remaining $97(21.9 \%)$ were not doing physical activity as per the recommendation.

\section{Factors affecting the level of physical activity during pregnancy}

Multivariable logistic regression was done by taking 10 variables in to account simultaneously. After testing for assumptions, logistic regression was conducted using the default method.

The half of variables which showed significant association with level of physical activity during pregnancy in bivariate analysis could not persist as significant in the multivariable analysis. These covariates were; ANC type, marital status, pregnancy intention, perceived benefit of activity and perceived barrier to exercise.

In the multivariable binary logistic regression analysis, only five variables had shown overall Significant effect on level of physical activity during pregnancy at 5\% level of significance.
Based on this, parity, maternal previous history of miscarriage, Education level of mothers, maternal age and occupation were variables which significantly associated with physical activity level (Table 3 ).

\section{Discussion}

This study was aimed to assess the level of physical activity and associated factors during pregnancy. Approximately three-fourths $(78.1 \%)$ of the women in this study physically active and the remaining 97 (21.9\%) [95\% CI $(.181, .258)]$ were not doing physical activity during pregnancy as per the recommendation. This is lower than the study findings of Ibadan (Nigeria) [18], Campinas (Brazil) [22], United States [23] and Ireland [24] which was 49.0\%, $30.8 \%, 77.5 \%$ and $78.5 \%$ respectively. The discrepancies in the level of physical activity between other studies and ours may be due to differences in sample characteristics, measurements used (subjective vs objective) and high altitude. Another possible reason is since more than half of the pregnant mothers are house wife and have low and middle income are less likely to outsource housework and other services. This could have raised the physical activity level of the women.

In addition, women in this study expended less total energy during pregnancy 141.23 MET-h/week (approximately 20.2 MET h/day) than pregnant women in the United States (25.4 MET h/day) [25], Australia (33.26 MET h/day) [26], Hong Kong (25.23 h/day) [27], Taiwan (35.9 MET-h/day) [28] and France (29.0 MET h/ day) [9] but it is more or less comparable with the studies conducted in Tianjin, China (18.50 to 21.90 MET h/ day) [29] and Japan (19.7 MET-h/day) [30]. This might be due to physical activity measurement methods were developed in economically developed countries with the assumptions about body weight. Maternal body weights are likely to be substantially lower in Ethiopia and so less energy is expended for the same level of physical activity.

In this study women expended highest amount of energy (69.4 MET-h/weeks) on household activities. This is comparable with the study conducted previously in Nigeria [18], Hong Kong [27] and Japan [30] which was 63.4 MET-h/week, 79.0 MET-h/week respectively. In addition the median amount of weekly energy expanded on occupation activity (60 MET-h/week) was significantly lower as compared to studies conducted previously in Taiwan (120 MET-h/week) [28] and but higher as compared to another study conducted in in Hong Kong (33.6 MET-h/week) [27] and Japan (00 MET-h/week) [30]. The observation that $56.7 \%$ of the pregnant women seen in this study were housewives, accounted for the low energy expenditure on occupational activity. In addition, most the pregnant women's usually take maternity leave early which may make 
Table 3 Bivariate and multivariable logistic regression analysis result of level of physical activity and associated factors during pregnancy among women who delivered in selected zonal Hospitals of Tigray, Ethiopia, $2017(n=442)$

\begin{tabular}{|c|c|c|c|c|c|c|}
\hline \multirow[t]{3}{*}{ Variable } & \multirow[t]{3}{*}{ Category } & \multirow[t]{3}{*}{ n (\%) } & \multicolumn{2}{|l|}{ Level of PA } & \multirow[t]{3}{*}{$\operatorname{COR}[95 \% \mathrm{Cl}]$} & \multirow[t]{3}{*}{$\operatorname{AOR}[95 \% \mathrm{Cl}]$} \\
\hline & & & Active & Inactive & & \\
\hline & & & $\mathrm{n}=345(\%)$ & $\mathrm{n}=97(\%)$ & & \\
\hline \multicolumn{7}{|c|}{ Age (years) } \\
\hline & $<19$ years & $36(8.1)$ & $22(6.4)$ & $14(14.4)$ & $2.630[1.206,5.737]^{*}$ & $4.673[1.431,15.254]^{* *}$ \\
\hline & $20-24$ & $134(31.0)$ & 107 (31.0) & $27(27.8)$ & $1.043[.584,1.864]$ & $1.570[.656,3.757]$ \\
\hline & $25-29$ & $154(34.8)$ & $124(35.9)$ & $30(30.9)$ & 1 & \\
\hline & $30-34$ & $81(18.3)$ & $69(20)$ & $12(12.4)$ & $.719[.346,1.494]$ & $1.948[.544,6.978]$ \\
\hline & $35-40$ & $137(8.4)$ & $23(6.7)$ & $14(14.4)$ & $2.516[1.159,5.460]^{*}$ & $3.348[.792,14.149]$ \\
\hline \multicolumn{7}{|c|}{ Marital status } \\
\hline & Married & $384(86.9)$ & 310 (89.9) & $74(76.3)$ & 1 & 1 \\
\hline & Never married & $30(6.8)$ & $15(4.3)$ & $15(15.5)$ & $4.189[1.961,8.951]^{*}$ & $3.191[.786,12.950]$ \\
\hline & Divorced/widowed & $28(6.3)$ & $20(5.8)$ & $8(8.2)$ & $1.676[.710,3.953]$ & $3.778[.844,16.902]$ \\
\hline \multicolumn{7}{|c|}{ Educational level } \\
\hline & Illiterate & $68(15.4)$ & $26(7.5)$ & $42(43.3)$ & $7.560[3.937,14.517]^{*}$ & 19. $359[4.926,76.077]^{* *}$ \\
\hline & Elementary school & $140(31.7)$ & $130(37.7)$ & $10(10.3)$ & $.360[.166, .781]^{*}$ & $.260[.087, .775]^{* *}$ \\
\hline & High school & $142(32.1)$ & 117 (33.9) & $25(25.8)$ & 1 & \\
\hline & College/university & $92(20.8)$ & $72(20.9)$ & $20(20.6)$ & $1.300[.674,2.508]$ & $1.699[.248,11.662]$ \\
\hline \multicolumn{7}{|c|}{ Occupation } \\
\hline & House wife & $150(33.9)$ & $95(27.5)$ & $55(56.7)$ & 1 & 1 \\
\hline & Govt. employee & $90(20.4)$ & $72(20.9)$ & $18(18.6)$ & $.432[.234, .798]^{*}$ & $1.617[.172,15.185]$ \\
\hline & Private employee & $63(14.3)$ & $55(15.9)$ & $08(8.2)$ & $.251[.111, .566]^{*}$ & $.655[.162,2.654]$ \\
\hline & Farmer & $95(21.5)$ & $91(26.4)$ & $04(4.1)$ & $.076[.026, .218]^{*}$ & $.015[.003, .083]^{* *}$ \\
\hline & Trader & $22(5.0)$ & $18(5.2)$ & $04(4.1)$ & $.384[.124,1.192]$ & $1.166[.242,5.614]$ \\
\hline & Student & $22(5.0)$ & $14(4.1)$ & $8(8.2)$ & $.987[.389,2.502]$ & $.864[.170,4.396]$ \\
\hline \multicolumn{7}{|l|}{ ANC type } \\
\hline & Public ANC & $286(66.5)$ & $212(61.4)$ & $74(76.3)$ & 1 & \\
\hline & Private ANC & $144(33.5)$ & $123(35.7)$ & $21(21.6$ & $.489[.287, .834]^{*}$ & $.934[.414,2.107]$ \\
\hline & No ANC & $12(2.7)$ & $10(2.9)$ & $2(2.1)$ & $.573[.123,2.676]$ & $.675[.077,5.896]$ \\
\hline \multicolumn{7}{|c|}{ Pregnancy intention } \\
\hline & Planned & $341(77.1)$ & $290(84.1)$ & $51(52.6)$ & 1 & \\
\hline & Unplanned & $101(22.9)$ & $55(15.9)$ & $46(47.4)$ & $4.756[2.908,7.777]^{*}$ & $1.450[.567,3.713]$ \\
\hline \multicolumn{7}{|l|}{ Parity } \\
\hline & Primipara & $195(44.1)$ & $125(36.2)$ & $70(72.2)$ & $4.563[2.781,7.488]^{*}$ & $7.677[3.193,18.459]^{* *}$ \\
\hline & Multipara & $247(55.9)$ & $220(63.8)$ & $27(27.8)$ & 1 & \\
\hline \multicolumn{7}{|c|}{ History of miscarriage } \\
\hline & No & $352(79.6)$ & $288(83.5)$ & $64(66.0)$ & 1 & \\
\hline & Yes & $90(20.4)$ & $57(16.5)$ & $33(34)$ & $2.605[1.569,4.326]^{*}$ & $8.045[3.325,19.465]^{* *}$ \\
\hline \multicolumn{7}{|c|}{ Perceived benefit (s) of PA } \\
\hline & Improve general health of mother & $120(66 \%)$ & $97(28.1)$ & $23(23.7)$ & 1 & \\
\hline & Shortened delivery process & 19 (10.2\%) & $17(4.9)$ & $2(2.1)$ & $.496[.107,2.301]$ & $.463[.081,2.638]$ \\
\hline & Minimize excessive GWG & $31(16.7 \%)$ & $26(7.5)$ & $5(5.2)$ & $.811[.281,2.340]$ & $1.077[.286,4.052]$ \\
\hline & Others $^{c}$ & $16(8.6 \%)$ & $12(3.5)$ & $4(4.1)$ & $1.406[.415,4.759]$ & $.839[.168,4.194]$ \\
\hline & No benefit & $256(57.9)$ & $193(55.9)$ & $63(64.9)$ & $1.377[.805,2.353]$ & $1.999[.599,6.675]$ \\
\hline \multicolumn{7}{|c|}{ Perceived barrier to exercise } \\
\hline & Lack of exercise knowledge & 160 & $128(37.1)$ & $329(33)$ & 1 & \\
\hline & Have no exercise habit & 51 & $35(10.1)$ & $16(16.5)$ & $1.829[.902,3.708]$ & $.460[.119,1.786]$ \\
\hline & Fear of miscarriage & 33 & $25(7.2)$ & $8(8.2)$ & $1.280[.528,3.103]$ & $.493[.097,2.519]$ \\
\hline & Others & 32 & $18(5.2)$ & $14(14.4)$ & $3.111[1.400,6.915]^{*}$ & $1.378[.309,6.140]$ \\
\hline & No barrier & 166 & $139(40.3)$ & $27(27.8)$ & $.777[.441,1.368]$ & $.534[.124,2.295]$ \\
\hline
\end{tabular}

$A O R$ adjusted odds ratio, $C O R$ crude odds ratio

* P value $<.05$ in the bivariate analysis

** $\mathrm{P}$ value $<.05$ in the multivariable analysis 
them spend more time at home than at work. Another possible reason is that most of the pregnant women may feel more comfortable and safer doing household activities than engaging in occupational or sports activities during pregnancy.

This study also showed that primiparous women were 7.68 times more likely to be inactive as compared to multiparous women. This finding is in agreement with prior studies in Nigeria [18], Brazil [31], Massachusetts [32], Botucatu [6], Iowa State (USA), Halifax (Canada), Boston (USA) [25, 33, 34]. This because mothering higher numbers of children requires higher level of activity.

Education level of mothers also had significant association with women's level of physical activity during pregnancy. Women's with no formal education were more likely to be in active. Similar findings were also observed in the earlier studies from Australia [35], Brazil [31], Rio Grande [36], Durham [37], Canada [26, 33]. This may be related to the possibility that women with higher educational levels are better informed or have more access to knowledge about physical activity during pregnancy.

Those Women who were engaged in manual occupation were less likely to be physically inactive during pregnancy. This is in line with those of earlier study in Hamadan (Iran) [38], USA [39]. This might be due to the fact that daily occupational activity in Ethiopia use more energy because of the lack of labor saving devices. Another possible reason is because much of Ethiopia is at high altitude, equivalent activity requires greater effort and more energy than it does at sea level. Therefore, women's living in Ethiopia show high energy expenditure and this may exceed energy intake significantly.

In addition, those women with history of miscarriage had 8.05 times higher odds of becoming physically inactive during pregnancy as compared to those without history of miscarriage $[\mathrm{AOR}=8.045 ; 95 \%$ CI $(3.325$, 19.465)]. This is consistent with the study conducted in Kwun Tong (Hong Kong), Denmark [27, 40]. This might be due to the reason that fear of harming the baby during physical activity and due to the fact that women with previous history of miscarriage are concerned that regular physical activity during pregnancy may cause another miscarriage, poor fetal growth. In addition, the lower levels of physical activity associated with previous miscarriage may be related to prenatal and neonatal practitioners' advice for more bed rest for women with a history of pre-eclampsia. Thus, they are more likely to become inactive during pregnancy.

This study also showed that women's whose age was $<19$ years had, 4.7 times higher odds of becoming physically inactive during pregnancy as compared those mothers who were in the age range of $25-29$ years $[\mathrm{AOR}=4.673$; 95\% CI $(1.431,15.254)]$. The findings of the present study are consistent with those of earlier studies that has reported PA association with age Australia, St. Louis (USA), Halifax (Canada), Chapel Hill (USA) [26, 33, 39, 41].

\section{Conclusion}

In conclusion, this study revealed that only about less than one fourth women were in active and most of the physical activities were done during performance of household activities and occupational activity, but there was very little participation in the exercise/leisure time activity domain. On the other hand, this study has also found that both maternal socio-demographic and obstetric factors had contributed for pregnant women's level of activity.

\section{Limitation}

Lack of abundant previous similar study in Africa made comparison difficult and Self-reported measure of physical activity may lead to recall bias.

\section{Additional file}

Additional file 1. Pregnancy physical activity questionnaire.

\section{Abbreviations}

AOR: adjusted odds ratios; ACOG: American college of obstetricians and gynecologists; ACSM: American college of sports medicine; ANC: antenatal care; CDC: centers for disease control and prevention; $\mathrm{Cl}$ : confidence interval; COR: crude odds ratios; IQ: interquartile; MET: metabolic equivalent task; NGO: Non-Governmental Organization; PA: physical activity; PPAQ: pregnant physical activity questionnaire; SD: standard deviation.

\section{Acknowledgements}

Our deepest gratitude goes to Mekelle University, Department of Nursing for financial support. We would like to extend our sincere gratitude to the data collectors, supervisors and the study participants for being involved in the study.

\section{Authors' contributions}

DG conceived and designed the study, analyzed the data and wrote the manuscript. HB and MK Data analysis, drafting of the manuscript and advising the whole research paper. EB were involved in the interpretation of the data and contributed to manuscript preparation. DG, EB involve in Tittle selection, Data analysis, drafting of the manuscript. All authors read and approved the final manuscript.

\section{Funding}

There is no funding for this research. All cost of data collection and analysis were covered by the authors.

\section{Availability of data and materials}

All the necessary data and materials of this study are readily available in the additional material section of the journal of BMC in Research Note.

\section{Ethics approval and consent to participate}

Ethical clearance was received from Institutional Review Board of the College and full written informed consent was obtained from participants. Privacy and strict confidentiality were maintained during the data collection process. No personal details were recorded or produced on any documentation related to the study. We declare that all necessary data's and materials are available in the manuscript and support information section of BMC in research note. 


\section{Consent for publication \\ Not applicable.}

\section{Competing interests}

The authors declare that they have no competing interests.

\author{
Author details \\ ${ }^{1}$ Lecturer at Nursing School, College of Health Science, Aksum University, \\ Aksum, Ethiopia. ${ }^{2}$ School of Nursing, College of Health Science, Mekelle \\ University, Mekelle, Ethiopia.
}

Received: 4 June 2019 Accepted: 17 July 2019

Published online: 23 July 2019

\section{References}

1. Caspersen CJ, Powell KE, Christenson GM. Physical activity, exercise, and physical fitness: definitions and distinctions for health-related research. Public Health Rep. 1985;100:126-30.

2. Tobias DK, Zang C, Van Dam RM, Bowers K. Physical activity before and during pregnancy and risk of gestational diabetes mellitus. Diabetes Care 2010;34:223-39.

3. Organization $\mathrm{WH}$. Global recommendations on physical activity for health. Geneva: WHO; 2011

4. Gynecologists (ACOG) ACoOa. Exercise during pregnancy and the postpartum period. Int J Gynaecol Obstet. 2002;77(1):79-81.

5. Organization WH. Global recommendations on physical activity for health. Geneva:WHO Press; 2010.

6. Carvalhaes MA, Martiniano AC. Physical activity in pregnant women receiving care in primary health care units. Rev Saude Publica. 2013;47:958-67 (in Portuguese).

7. Harrod CS, Chasan-Taber L, Reynolds RM. Physical activity in pregnancy and neonatal body composition: the healthy start study. Obstet Gynecol. 2014;124:257-64

8. Amezcua-Prieto C, Lardelli-Claret P, Olmedo-Requena R. Compliance with leisure-time physical activity recommendations in pregnant women. Acta Obstet Gynecol Scand. 2011;90:245-52.

9. Chandonnet N, Saey D, Alméras N, French MI. Pregnancy physical activity questionnaire compared with an accelerometer cut point to classify physical activity among pregnant obese women. PLOS ONE. 2012;7(6):e38818.

10. Liu J, Blair S, Teng Y. Physical activity during pregnancy in a prospective cohort of British women: results from the Avon longitudinal study of parents and children. Eur J Epidemiol. 2011;26(3):237-47.

11. Hjorth MF, Kloster S, Girma T, Faurholt-Jepsen D. Level and intensity of objectively assessed physical activity among pregnant women from urban Ethiopia. BMC Preg Childb. 2012;12:154.

12. $\mathrm{ACoOaG}$. Exercise during pregnancy and the postnatal period. Washington: ACoOaG; 1985

13. Shangold MM. Exercise during pregnancy: current state of the art. Can Fam Phys. 1989;35:1675

14. Kieffer EC, Willis SK, Arellano N, Guzman R. Perspectives of pregnant and postpartum Latino women on diabetes, physical activity, and health. Health Educ Behav. 2002;29(5):542-56.

15. Guelinckx IDR, Mullie P, Vansant G. Effect of lifestyle intervention on dietary habits, physical activity, and gestational weight gain in obese pregnant women. Am J Clin Nutr. 2010;91:373-80.

16. Rao S, Kanade A, Margetts BM, Yajnik CS, Lubree H, Rege S, Desai B, Jackson A, Fall CH. Maternal activity in relation to birth size in rural India: the Pune Maternal Nutrition Study. Eur J Clin Nutr Fall. 2003;57(4):531-42.

17. Dye TD, Knox KL, Artal R, Aubry RH, Wojtowycz MA. Physical activity, obesity, and diabetes in pregnancy. Am J Epidemiol. 1997;146(11):961-5.

18. Adeniyi AF, Ogwumike OO, Osinike Cl. Physical activity and energy expenditure: findings from the Ibadan Pregnant Women's Survey. Afr J Reprod Health. 2014;18(2):117-26.

19. Agency FDRoECS. Population projection of Ethiopia for all regions at Wezreda level from 2014-2017. Addis Abeba: Agency FDRoECS; 2013.

20. Chasan-Taber L, Schmidt MD, Roberts DE. Development and validation of a pregnancy physical activity questionnaire. Med Sci Sports Exerc 2004;36:1750-60.
21. Ainsworth BE, Haskell WL, Herrmann SD. Compendium of physical activities: a second update of codes and MET values. Med Sci Sports Exerc. 2011:43(8):1575-81.

22. Brunette EL, Kotze J, Wood PS, Du Toit P, Grant CC. An epidemiological study of physical activity patterns and weight gain in physically active and sedentary pregnant women in Tshwane, South Africa. Afr J Phys Health Educ Recreat Dance. 2012;18(Supplement 1):132-43.

23. Evenson KR, Huston sl. Leisure-time physical activity among pregnant women in the US. Paediatr Perinat Epidemiol. 2004;18(6):400-7.

24. Walsh JMMC, Byrne J, et al. Prevalence of physical activity among healthy pregnant women in Ireland. Int JGynaecol Obstet. 2011;114(2):154-5.

25. Smith KM, Campbell CG. Physical activity during pregnancy: impact of applying different physical activity guidelines. J Preg. 2013;2013:3.

26. Schmidt MD, Pekow P, Freedson PS, Markenson G, Chasan-Taber L. Physical activity patterns during pregnancy in a diverse population of women. J Womens Health. 2006;15(8):909-18.

27. Wing-Man P, Chuang S, Chan L, Lin-Wai C, et al. Physical activity in pregnancy: attitudes and practices of Hong Kong Chinese women. Hong Kong J Gynaecol Obstet Midwifery. 2015;15(2):138-47.

28. Lee CF, Chiang IC, Lin SS, Lin HM, Hsu CJ. Physical activity pattern and related factors among women during pregnancy. Formosan J Med. 2012;16(2):103-11.

29. Zhang Y, Dong S, Zuo J. Physical activity level of urban pregnant women in tianjin, china: a cross-sectional study. PLoS ONE. 2014;9(10):e109624. https://doi.org/10.1371/journalpone0109624.

30. Matsuzaki M, Haruna M, Nakayama K, Shiraishi M, Ota E, Murayama R, Murashima S, Yeo S. Adapting the pregnancy physical activity questionnaire for Japanese pregnant women. J Obstet Gynecol Neonatal Nurs. 2014:43(1):107-16.

31. Nascimento SL, Surita FG, Godoy AC, Kasawara KT, Morais SS. Physical activity patterns and factors related to exercise during pregnancy: a cross sectional study. PLoS ONE. 2015;10(6):e0128953.

32. Lynch KE, Landsbaugh JR, Whitcomb BW. Physical activity of pregnant Hispanic women. Am J Prev Med. 2012;43:434-9.

33. Fell DB, Joseph KS, Armson BA, Dodds L. The impact of pregnancy on physical activity level. Matern Child Health J. 2009;13(5):597.

34. Pereira MA, Rifas-Shiman SL, Kleinman KP, Rich-Edwards JW, Peterson KE, Gillman MW. Predictors of change in physical activity during and after pregnancy: project Viva. Am J Prev Med. 2007;32:312-9.

35. Foxcroft KF, Rowlands IJ, Byrne NM, McIntyre HD, Callaway LK. Exercise in obese pregnant women: the role of social factors, lifestyle and pregnancy symptoms. BMC Preg Childb. 2011;11(1):4.

36. Dumith SC, Domingues MR, Mendoza-Sassi RA, Cesar JA. Physical activity during pregnancy and its association with maternal and child health indicators. Rev Saúde Pública. 2012;46(2):327-33.

37. Jukic AM, Evenson KR, Herring AH, Wilcox AJ, Hartmann KE, Daniels JL. Correlates of physical activity at two time points during pregnancy. J Phys Act Health. 2012;9(3):325-35.

38. Hazavehie SM, Otogara M, Moeini B, Roshanaei G, Kafami V. Physical activity and its related factors among female employees: applying BASNEF model. J Res Health. 2013:3(4):551-7.

39. Petersen AM, Leet TL, Brownson RC. Correlates of physical activity among pregnant women in the United States. Med Sci Sports Exerc. 2005;37(10):1748-53

40. Hegaard HK, Kjaergaard H, Damm PP, Petersson K, Dykes AK. Experiences of physical activity during pregnancy in Danish nulliparous women with a physically active life before pregnancy. A qualitative study. BMC Preg Childb. 2010;10(1):33.

41. Evenson KR, Wen F. National trends in self-reported physical activity and sedentary behaviors among pregnant women. NHANES 1999-2006. Prev Med (Baltim). 2010;50(3):123-8.

\section{Publisher's Note}

Springer Nature remains neutral with regard to jurisdictional claims in published maps and institutional affiliations. 